\title{
ANALISA KOMPARASI NEURAL NETWORK BACKPROPAGATION DAN MULTIPLE LINEAR REGRESSION UNTUK PERAMALAN TINGKAT INFLASI
}

\author{
Amrin $^{1}$
}

\begin{abstract}
The inflation rate can not be underestimated in a country's economic system and businesses in general. If inflation can be predicted with high accuracy, of course, can be used as the basis of government policy making in anticipation of future economic activity. In this study will be used back propagation neural network method and multiple linear regression method to predict the monthly inflation rate in Indonesia, then compare which method is the better. The data used comes from the central statistical agency in 2006-2015, which is $80 \%$ as training data and $20 \%$ as testing data. In the results of the data analysis is concluded that the performance of multiple linear regression is better than back propagatin neural network, with a mean absolute deviation (MAD) is 0.0380, a mean square error (MSE) is 0.0023, and a Root Mean Square Error (RMSE) is 0.0481 .
\end{abstract}

Keywords: Inflation, neural network backpropagation, multiple linear regression, mean square error.

Intisari-Tingkat inflasi tidak dapat dianggap remeh dalam sistem perekonomian suatu negara dan pelaku bisnis pada umumnya. Jika inflasi dapat diramalkan dengan akurasi yang tinggi, tentunya dapat dijadikan dasar pengambilan kebijakan pemerintah dalam mengantisipasi aktivitas ekonomi di masa depan. Pada penelitian ini akan digunakan metode prediksi neural network backpropagation dan multiple linear regression untuk memprediksi tingkat inflasi bulanan di indonesia, selanjutnya membandingkan manakah yang terbaik dari kedua metode tersebut. Data inflasi yang digunakan bersumber dari Badan Pusat Statistik dari tahun 2006-2015, dimana $80 \%$ sebagai data training dan $20 \%$ sebagai data testing. Dari hasil analisis data yang dilakukan disimpulkan bahwa Performa model multiple linear regression lebih baik dibandingkan dengan metode neural network backpropagation dengan nilai mean absolute deviation (MAD) sebesar 0.0380, mean square error (MSE) sebesar 0.0023, dan nilai Root Mean Square Error (RMSE) sebesar 0.0481.

Kata kunci: Inflasi, neural network backpropagation, multiple linear regression, mean square error.

\footnotetext{
1 Jurusan Teknik Komputer AMIK BSI Jakarta, Jln. R.S Fatmawati no. 24 Pondok Labu Jakarta Selatan (telp: 0217504878 fax:021-7313790: e-mail:amrin.ain@bsi.ac.id
}

\section{Pendahuluan}

"Inflasi adalah kenaikan harga barang dan jasa secara umum dimana barang dan jasa tersebut merupakan kebutuhan pokok masyarakat atau turunnya daya jual mata uang suatu negara. Kestabilan inflasi merupakan prasyarat bagi pertumbuhan ekonomi yang berkesinambungan yang pada akhirnya memberikan manfaat bagi peningkatan kesejahteraan masyarakat. Pentingnya pengendalian inflasi didasarkan pada pertimbangan bahwa inflasi yang tinggi dan tidak stabil memberikan dampak negatif kepada kondisi sosial ekonomi masyarakat"'[1].

Penelitian mengenai peramalan inflasi di suatu negara mendapatkan perhatian yang positif bagi peneliti makroekonomi. Sebagian besar bank sentral menggunakan inflasi sebagai salah satu pertimbangan untuk mengambil kebijakan moneter. Kebijakan moneter diambil dengan pertimbangan nilai inflasi yang akan datang. Nilai inflasi sekarang, merupakan hasil dari kebijakan yang lalu, mungkin hanya memberikan informasi yang samar-samar. Bagi pemerintah, peramalan inflasi merupakan jembatan penghubung untuk mengetahui nilai inflasi yang akan datang. Penelitian ini merupakan pengembangan peramalan inflasi di Indonesia yang dapat memberikan input bagi Bank Indonesia sebagai pertimbangan pengambilan kebijakan.

Pada penelitian ini akan digunakan metode prediksi neural network backpropagation dan multiple linear regression, untuk memprediksi tingkat inflasi bulanan dan membandingkan metode manakah yang terbaik dari kedua metode tersebut. Data yang penulis gunakan adalah data tingkat inflasi bulanan di indonesia yang dikeluarkan oleh Badan Pusat Statistik dan Bank Indonesia.

Kelebihan metode neural network backpropagation dan multiple linear regression diantaranya melakukan generalisasi dan ekstraksi dari pola data tertentu, mampu mengakuisisi pengetahuan walau tidak ada kepastian, menyelesaikan masalah yang tidak terstruktur dan sulit didefinisikan, dan mampu melakukan perhitungan secara paralel sehingga proses lebih singkat.

\section{KAJIAN LITERATUR}

1. Data Mining

"Data mining adalah rangkaian proses untuk menggali nilai tambah berupa informasi yang belum terekplorasi dari sebuah basis data, melakukan ekplorasi dengan cara-cara tertentu untuk memanipulasi data menjadi informasi yang 
lebih berharga dengan cara mengektraksi dan mengenali pola penting dari basis data" [2]. "Data mining adalah perpaduan dari ilmu statistik, kecerdasan buatan, dan penelitian bidang database" [3]. "Nama data mining berasal dari kemiripan antara pencarian informasi yang bernilai dari database yang besar dengan menambang sebuah gunung untuk sesuatu yang bernilai" [4].

"Data Mining merupakan teknologi baru yang sangat berguna untuk membantu perusahaan-perusahaan menemukan informasi yang sangat penting dari gudang data mereka. Beberapa aplikasi data mining fokus pada prediksi, mereka meramalkan apa yang akan terjadi dalam situasi baru dari data yang menggambarkan apa yang terjadi di masa lalu" [5].

2. Neural Network

"Neural network atau jaringan syaraf tiruan adalah merupakan salah satu representasi buatan dan otak manusia yang selalu mencoba mensimulasikan proses pembelajaran pada otak manusia. Istilah buatan disini digunakan karena jaringan syaraf ini diimplementasikan dengan menggunakan program komputer yang mampu menyelesaikan sejumlah proses perhitungan selama proses pembelajaran. Neural network adalah satu set unit input/output yang terhubung dimana tiap relasinya memiliki bobot"'[6].

"Neural Network dimaksudkan untuk mensimulasikan perilaku sistem biologi susunan syaraf manusia, yang terdiri dari sejumlah besar unit pemroses yang disebut neuron, yang beroperasi secara paralel"[7]. "Neuron mempunyai relasi dengan synapse yang mengelilingi neuron-neuron lainnya. Susunan syaraf tersebut dipresentasikan dalam neural network berupa graf yang terdiri dari simpul (neuron) yang dihubungkan dengan busur, yang berkorespondensi dengan synapse. Sejak tahun 1950-an, neural network telah digunakan untuk tujuan prediksi, bukan hanya klasifikasi tapi juga untuk regresi dengan atribut target kontinu" [8].

"Neural network terdiri dari dua lapisan atau lebih, meskipun sebagian besar jaringan terdiri dari tiga lapisan : lapisan input, lapisan tersembunyi, dan lapisan output" [9]. "Pendekatan neural network dimotivasi oleh jaringan saraf biologis. Secara kasar, neural network adalah satu set terhubung input/output unit, dimana masing-masing sambungan memiliki berat yang terkait dengannya. Neural network memiliki beberapa ciri yang membuat mereka populer untuk clustering. Pertama, neural network adalah arsitektur pengolahan inheren paralel dan terdistribusi. Kedua, neural network belajar dengan menyesuaikan bobot interkoneksi dengan data, Hal ini memungkinkan neural network untuk "menormalkan" pola dan bertindak sebagai fitur (atribut) extractors untuk kelompok yang berbeda. Ketiga, neural network memproses vektor numerik dan membutuhkan pola objek untuk diwakili oleh fitur kuantitatif saja" [10].

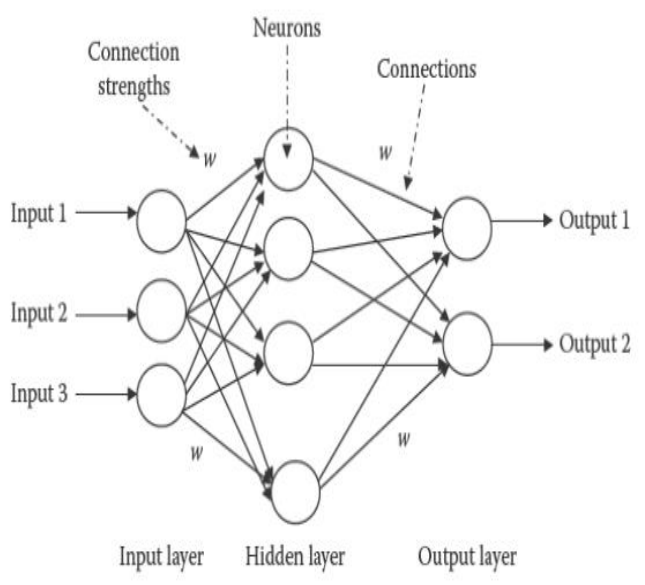

Sumber: Shukla et al. (2010)

Gambar 1

Arsitektur Neural Network

\section{Algoritma Neural Network Backpropagation}

"Backpropagation merupakan salah satu algoritma pembelajaran dalam jaringan syaraf tiruan. Proses pembelajaran dalam backpropagation dilakukan dengan penyesuaian bobot-bobot jaringan syaraf tiruan dengan arah mundur berdasarkan nilai error dalam proses pembelajaran (Kusrini, 2009). Penemuan algoritma backpropagation untuk multilayer perceptron (MLP), merupakan metode yang sistematis untuk training sehingga bisa dilakukan dan lebih efisien. Algoritma backpropagation berasal dari learning rule Widrow dan Hoff, disusun oleh Werbos (1974), dibuat oleh Parker (1985), Rumelhart Hinton, Williams (Rumelhart dan Williams, 1986) dan peneliti lainnya" [11].

"Algoritma pelatihan backpropagation terdiri dari dua tahapan yaitu feedforward dan backpropagation dari galatnya. Langkah pembelajaran dalam algoritma backpropagation adalah sebagai berikut" [6]:

- Inisialisasi bobot (ambil bobot awal dengan nilai random yang cukup kecil).

- Kerjakan langkah-langkah berikut selama kondisi berhenti bernilai FALSE:

1) Untuk tiap-tiap pasangan elemen yang akan dilakukan pembelaajaran, kerjakan:

Feedforward:

a. Tiap-tiap unit input (Xi, $\mathrm{i}=1,2,3, \ldots, \mathrm{n})$ menerima sinyal $\mathrm{x}_{\mathrm{i}}$ dan meneruskan sinyal tersebut ke semua unit pada lapisan yang ada di atasnya (lapisan tersembunyi).

b. Tiap-tiap unit tersembunyi $(\mathrm{Zj}, \mathrm{j}=1,2,3, \ldots, \mathrm{p})$ menjumlahkan sinyal-sinyal input terbobot:

$$
\mathrm{z}_{-} \mathrm{in}_{\mathrm{j}}=\mathrm{v} 0_{\mathrm{j}}+\sum \mathrm{x}_{\mathrm{i}} \mathrm{vi}_{\mathrm{j}}
$$

Gunakan fungsi aktivitas untuk menghitung sinyal outputnya:

$$
\mathrm{z}_{\mathrm{j}}=\mathrm{f}\left(\mathrm{z} \_ \text {in } \mathrm{n}_{\mathrm{j}}\right)
$$


Kirimkan sinyal tersebut ke semua unit dilapisan atasanya (unit-unit output)

c. Tiap-tiap unit output $\left(\mathrm{Y}_{\mathrm{k}}, \mathrm{k}=1,2, \ldots \ldots, \mathrm{m}\right)$ menjumlah sinyal-sinyal input terbobot

$$
\mathrm{y}_{-} \mathrm{in}_{\mathrm{k}}=\mathrm{wO}_{\mathrm{k}}+\sum \mathrm{z}_{\mathrm{j}} \mathrm{w}_{\mathrm{jk}}
$$

Gunakan fungsi aktivitas untuk menghitung sinyal output:

$$
\mathrm{y}_{\mathrm{k}}=\mathrm{f}\left(\mathrm{y} \_\mathrm{in}_{\mathrm{k}}\right)
$$

Dan kirimkan sinyal tersebut ke semua unit dilapisan atasnya (unit-unit output).

\section{Backpropagation}

d. Tiap-tiap unit output $(\mathrm{Yk}, \mathrm{k}=1,2, \ldots \ldots ., \mathrm{m})$ menerima target pola yang berhubungan dengan pola input pembelajaran, hitung informasi errornya:

$$
\delta_{k}=\left(t_{k}-y_{k}\right) f^{\prime}\left(y-i n_{k}\right)
$$

Kemudian hitung koreksi bobot (yang nanti akan digunakan untuk memperbaiki nilai $\left.\mathrm{w}_{\mathrm{jk}}\right)$ :

$$
\Delta \mathrm{w}_{\mathrm{jk}}=\alpha \delta_{\mathrm{k}} \mathrm{z}_{\mathrm{j}}
$$

Hitung juga koreksi bias (yang nantinya akan digunakan untuk memperbaiki nilai $\mathrm{w}_{0 \mathrm{k}}$ ):

Kirimkan $\delta_{\mathrm{k}}$ ini ke unit-unit yang ada dilapisan bawahnya.

e. Tiap-tiap unit tersembunyi $(\mathrm{Zj}, \mathrm{j}=1,2,3, \ldots, \mathrm{p})$

menjumlahkan delta inputnya (dari unit-unit yang

berada pada lapisan di atasanya):

$$
\delta \_\mathrm{in}_{\mathrm{j}}=\delta_{\mathrm{k}} \mathrm{W}_{\mathrm{ij}}
$$

Kalikan nilai ini dengan turunan dari fungsi aktivasi untuk menghitung informasi error:

$$
\delta_{\mathrm{j}}=\delta \_\mathrm{in}_{\mathrm{j}} \mathrm{f}^{\prime}\left(\mathrm{z} \_\mathrm{in} \mathrm{n}_{\mathrm{j}}\right)
$$

Kemudian hitung koreksi bobot untuk memperbaiki nilai $\mathrm{v}_{\mathrm{ij}}$ :

$$
\Delta \mathrm{v}_{\mathrm{ij}}=\alpha \delta_{\mathrm{j}} \mathrm{x}_{\mathrm{i}}
$$

Hitung juga koreksi bias untuk memperbaiki nilai $\mathrm{v}_{0 \mathrm{j}}$ :

$$
\Delta \mathrm{v}_{0 \mathrm{j}}=\alpha \delta \mathrm{j}
$$

f. Tiap-tiap unit output $\left(\mathrm{Y}_{\mathrm{k}}, \mathrm{k}=1,2, . \mathrm{m}\right)$ memperbaiki

bias dan bobotnya $(j=0,1,2, \ldots p)$

$$
\mathrm{w}_{\mathrm{jk}}(\text { baru })=\mathrm{w}_{\mathrm{jk}}(\text { lama })+\Delta \mathrm{w}_{\mathrm{jk}}
$$

Tiap-tiap unit tersembunyi $(\mathrm{Zj}, \mathrm{j}=1,2, \ldots, \mathrm{p})$ memperbaki bias dan bobotnya $(\mathrm{i}=0,1,2, \ldots \mathrm{n})$.

$$
\mathrm{v}_{\mathrm{ij}}(\text { baru })=\mathrm{v}_{\mathrm{ij}}(\text { lama })+\Delta \mathrm{v}_{\mathrm{ij}}
$$

2) Tes kondisi berhenti

\section{Multiple Linear Regression}

"Analisa Multiple Linear Regression atau dikenal regresi linier ganda digunakan oleh peneliti, bila peneliti bermaksud meramalkan bagaimana keadaan (naik turunnya) variabel dependen, bila dua atau lebih variabel independen sebagai faktor prediktor dimanipulasi (dinaik turubkan nilainya). Bentuk umum persamaan regresi linier ganda sebagai berikut" [12]:

$\mathrm{Y}=\mathrm{a}+\mathrm{b}_{1} \mathrm{X}_{1}+\mathrm{b}_{2} \mathrm{X}_{2}+\ldots+\mathrm{b}_{\mathrm{n}} \mathrm{X}_{\mathrm{n}}$
Data primer adalah data yang dikumpulkan langsung oleh peneliti dari responden, dan bukan berasal dari pengumpulan data yang pernah dilakukan sebelumnya. Data primer adalah data yang diperoleh dari sumber-sumber asli. Sumber asli disini diartikan sebagai sumber pertama darimana data tersebut diperoleh.

b. Data Sekunder

Data sekunder adalah data yang telah diolah dari data primer. Contoh: data kependudukan yang dikeluarkan oleh Badan Pusat Statistik (BPS). Pada penelitian ini penulis menggunakan data sekunder, yaitu data inflasi bulanan indonesia menurut kelompok pengeluaran tahun 2006-2015 yang dikeluarkan oleh BPS lewat website resminya (www.bps.go.id, 2015). Jenis data sekunder yang lain pada penelitian ini adalah semua pustaka dan laporan penelitian yang telah dilakukan baik dalam bentuk jurnal maupun kumpulan seminar nasional yang berhubungan dengan peramalan tingkat inflasi.

\section{c. Tahap Penelitian}

"Terdapat beberapa tahap dalam pengolahan data eksperimen, pada penelitian ini menggunakan model CrossStandard Industry for Data Mining (CRISP-DM)" [10], yaitu seperti terlihat pada diagram di bawah ini:

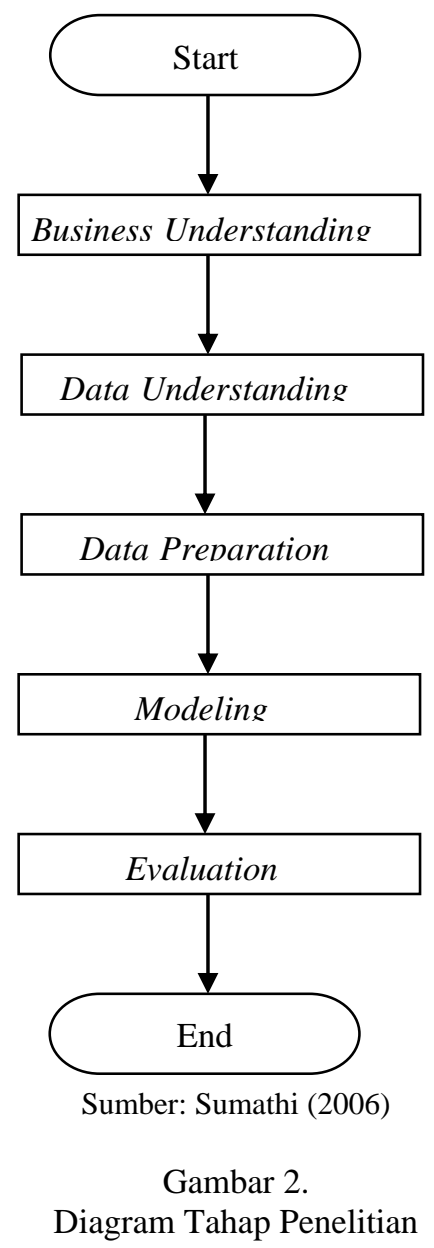

\section{Hasil Dan Pembahasan}

a. Data Primer 


\section{Neural Network Backpropagation}

Data yang diperoleh untuk penelitian ini sebanyak 118 record, dimana $80 \%$ dari data tersebut sebagai data training, dan $20 \%$ dari data sebagai data testing. Variabel input pada penelitian ini terdiri dari tujuh variabel, yaitu: 1). Inflasi Makanan, 2). Inflasi Makanan Jadi, Minuman, Rokok, dan Tembakau, 3). Inflasi Perumahan, Air, Listrrik, Gas, dan Bahan Bakar, 4). Inflasi Sandang, 5). Inflasi Kesehatan, 6). Inflasi Pendidikan, Rekreasi, dan Olahraga, 7). Inflasi Transpor, Komunikasi, dan Jasa Keuangan, Sedangkan variabel output adalah variabel Inflasi Umum. Perangkat lunak yang digunakan untuk menganalisa adalah mathlab versi 7.7.

Proses pelatihan jaringan syaraf tiruan menggunakan $80 \%$ dari total data, pada proses ini akan dilakukan pelatihan dengan arsitektur neural network yang berbeda-beda. Setiap arsitektur neural network akan menghasilkan bobot pelatihan yang terakhir yang akan digunakan sebagai bobot awal saat melakukan pengujian.

Hasil pelatihan oleh mathlab versi 7.7 untuk arsitektur jaringan 7-15-1 diperlihatkan oleh gambar di bawah ini:

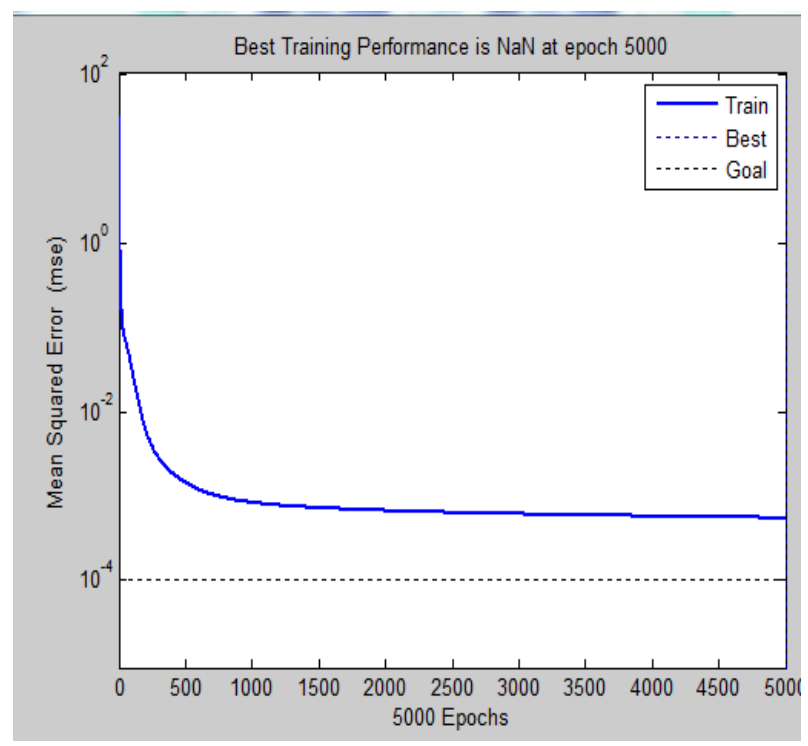

Sumber: Hasil Percobaan Menggunakan Mathlab 7.7

Gambar 3.

Mean Sequare Error dengan arsitektur Jaringan 7-15-1

Mencari network terbaik dilakukan dengan cara mengubah jumlah neuron/node pada lapisan tersembunyi secara trial and error, maka di dapatkan konfigurasi terbaik. Berikut tabel Mean Square Error (MSE) dari beberapa variasi jaringan yang dilatih menggunakan mathlab versi 7.7 pada data training dengan maximal epoch (iterasi) $=5000$, learning rate $(\alpha)=1$, momentum $=0.8$, dan target error $=0.0001$ :

Berdasarkan tabel 1, maka didapatkan konfigurasi jaringan terbaik sebagai berikut:

1. Jumlah neuron lapisan input $=7$

2. Jumlah neoron lapisan tersembunyi $=15$
3. Jumlah neuron lapisan output $=1$

Dengan nilai MSE sebesar 0,000540.

Arsitektur jaringan terbaik yang didapat saat pelatihan di atas akan digunakan sebagai arsitektur jaringan untuk mencari prediksi tingkat inflasi pada data testing. Bobot awal pada data testing adalah bobot terakhir saat pelatihan dari arsitektur jaringan terbaik.

Tabel 1.

Hasil Pelatihan Arsitektur Jaringan

\begin{tabular}{cc}
\hline Arsitektur Jaringan & MSE \\
\hline $7-1-1$ & 0,00142 \\
$7-2-1$ & 0,000745 \\
$7-3-1$ & 0,000974 \\
$7-4-1$ & 0,000568 \\
$7-5-1$ & 0,000668 \\
$7-10-1$ & 0,000680 \\
$7-15-1$ & $\mathbf{0 , 0 0 0 5 4 0}$ \\
$7-20-1$ & 0,00142 \\
$7-25-1$ & 0,00132 \\
$7-30-1$ & 0,292 \\
\hline
\end{tabular}

Sumber: Hasil Percobaan Menggunakan Mathlab 7.7

Hasil peramalan inflasi di Indosesia dengan metode Neural Network Backpropagation menggunakan mathlab versi 7.7 pada data testing diperlihatkan pada tabel di bawah ini:

Tabel 2.

Prediksi Inflasi Bulanan Indonesia dengan NN Backpropagation

\begin{tabular}{|c|c|c|c|c|}
\hline \multicolumn{2}{|c|}{ Tahun/Bulan } & \multirow{2}{*}{$\begin{array}{c}\text { Real } \\
1.0700\end{array}$} & \multirow{2}{*}{$\begin{array}{c}\text { Prediksi } \\
1.1707\end{array}$} & \multirow{2}{*}{$\begin{array}{c}\text { error } \\
-0.1007\end{array}$} \\
\hline 2014 & Januari & & & \\
\hline & Pebruari & 0.2600 & 0.2973 & -0.0373 \\
\hline & Maret & 0.0800 & 0.0814 & -0.0014 \\
\hline & April & -0.0200 & -0.0691 & 0.0491 \\
\hline & Mei & 0.1600 & 0.1484 & 0.0116 \\
\hline & Juni & 0.4300 & 0.4665 & -0.0365 \\
\hline & Juli & 0.9300 & 1.0043 & -0.0743 \\
\hline & Agustus & 0.4700 & 0.4668 & 0.0032 \\
\hline & September & 0.2700 & 0.2321 & 0.0379 \\
\hline & Oktober & 0.4700 & 0.4765 & -0.0065 \\
\hline & Nopember & 1.5000 & 1.5511 & -0.0511 \\
\hline & Desember & 2.4600 & 2.2157 & 0.2443 \\
\hline \multirow[t]{10}{*}{2015} & Januari & -0.2400 & -0.167 & -0.0730 \\
\hline & Pebruari & -0.3600 & -0.444 & 0.0840 \\
\hline & Maret & 0.1700 & 0.1281 & 0.0419 \\
\hline & April & 0.3600 & 0.1502 & 0.2098 \\
\hline & Mei & 0.5000 & 0.5417 & -0.0417 \\
\hline & Juni & 0.5400 & 0.5951 & -0.0551 \\
\hline & Juli & 0.9300 & 0.9644 & -0.0344 \\
\hline & Agustus & 0.3900 & 0.398 & -0.0080 \\
\hline & September & -0.0500 & -0.0316 & -0.0184 \\
\hline & Oktober & -0.0800 & -0.1285 & 0.0485 \\
\hline
\end{tabular}

Sumber: Hasil Pengujian Menggunakan Mathlab 7.7

\section{Multiple Linear Regression}

Variabel input pada metode multiple linear regression sama dengan metode neural network backpropagation terdiri 
dari tujuh variabel, yaitu: 1). Inflasi Makanan, 2). Inflasi Makanan Jadi, Minuman, Rokok, dan Tembakau, 3). Inflasi Perumahan, Air, Listrrik, Gas, dan Bahan Bakar, 4). Inflasi Sandang, 5). Inflasi Kesehatan, 6). Inflasi Pendidikan, Rekreasi, dan Olahraga, 7. Inflasi Transpor, Komunikasi, dan Jasa Keuangan, Sedangkan variabel output adalah variabel Inflasi Umum. Perangkat lunak yang digunakan untuk menganalisa adalah SPSS versi 17.0. Dengan menggunakan spss versi 17.0 tersebut diperoleh hasil pelatihan data training menghasilkan model persamaan regresi linier ganda sebagai berikut:

$$
\mathrm{Y}=0,241 \mathrm{X}_{1}+0,164 \mathrm{X}_{2}+0,271 \mathrm{X}_{3}+0,07 \mathrm{X}_{4}+0,040 \mathrm{X}_{5}+
$$$$
0,060 X_{6}+0,169 X 7-0,010
$$

Model regresi linier ganda tersebut kemudian diterapkan pada data testing. Hasilnya seperti diperlihatkan oleh tabel berikut ini:

Tabel 3.

Prediksi Inflasi Bulanan Indonesia dengan Multiple Linear Regression

\begin{tabular}{|c|c|c|c|c|}
\hline \multicolumn{2}{|c|}{ Tahun/Bulan } & \multirow{2}{*}{$\begin{array}{c}\text { Real } \\
1.0700\end{array}$} & \multirow{2}{*}{$\begin{array}{c}\text { Prediksi } \\
1.17\end{array}$} & \multirow{2}{*}{$\begin{array}{c}\text { error } \\
-0.0973\end{array}$} \\
\hline 2014 & Januari & & & \\
\hline & Pebruari & 0.2600 & 0.28 & -0.0200 \\
\hline & Maret & 0.0800 & 0.07 & 0.0112 \\
\hline & April & -0.0200 & -0.08 & 0.0560 \\
\hline & Mei & 0.1600 & 0.14 & 0.0219 \\
\hline & Juni & 0.4300 & 0.46 & -0.0297 \\
\hline & Juli & 0.9300 & 0.99 & -0.0643 \\
\hline & Agustus & 0.4700 & 0.46 & 0.0063 \\
\hline & September & 0.2700 & 0.24 & 0.0287 \\
\hline & Oktober & 0.4700 & 0.48 & -0.0122 \\
\hline & Nopember & 1.5000 & 1.50 & 0.0012 \\
\hline & Desember & 2.4600 & 2.51 & -0.0544 \\
\hline \multirow[t]{10}{*}{2015} & Januari & -0.2400 & -0.12 & -0.1167 \\
\hline & Pebruari & -0.3600 & -0.38 & 0.0175 \\
\hline & Maret & 0.1700 & 0.15 & 0.0212 \\
\hline & April & 0.3600 & 0.28 & 0.0796 \\
\hline & Mei & 0.5000 & 0.53 & -0.0283 \\
\hline & Juni & 0.5400 & 0.58 & -0.0433 \\
\hline & Juli & 0.9300 & 0.95 & -0.0218 \\
\hline & Agustus & 0.3900 & 0.40 & -0.0130 \\
\hline & September & -0.0500 & -0.09 & 0.0382 \\
\hline & Oktober & -0.0800 & -0.13 & 0.0534 \\
\hline
\end{tabular}

Sumber: Hasil Pengujian Menggunakan spss 17.0

3. Perbandingan Performa Model dan Grafik Model

a. Performa Model

untuk mengukur ketepatan dan keakuratan model prediksi inflasi bulanan di Indonesia ditentukan dengan menghitung nilai Mean Square Error (MSE), Root Mean Square Error (RMSE), dan Mean Absolute Deviation (MAD). Perbandingan dari kedua model diperlihatkan oleh tabel di bawah ini:

Tabel 4.

Perbandingan Performa Model

\begin{tabular}{ccc}
\hline \multirow{2}{*}{ Model } & NN & Multiple \\
& Backpropagation & Linear \\
& Regression \\
\hline
\end{tabular}

\begin{tabular}{ccc}
\hline MAD & 0.0577 & 0.0380 \\
MSE & 0.0069 & 0.0023 \\
RMSE & 0.0830 & 0.0481 \\
\hline
\end{tabular}

Tabel di atas memperlihatkan bahwa metode multiple linear regression lebih baik dibandingkan dengan metode neural network backpropagation dalam meramal inflasi bulanan indonesia.

b. Grafik Performa Model

Untuk grafik performa model jaringan neural network struktur backpropagation dan fuzzy logic mamdani diperlihatkan oleh gambar di bawah ini:

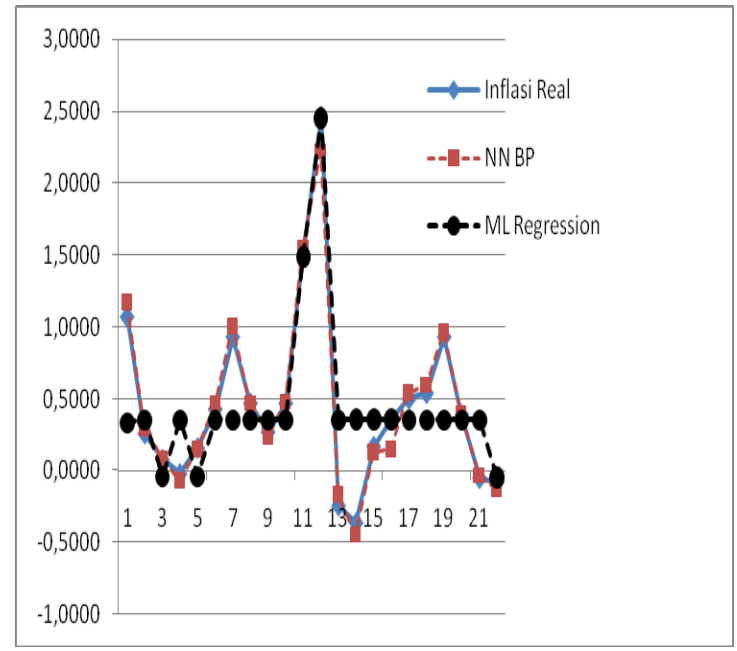

Gambar 4

Perbandingan Antara Neural Network Backpropagation dan Multiple Linear Regression

\section{KeSimpulan}

Berdasarkan analisis data yang telah dilakukan dapat disimpulkan bahwa:

1. Performa model neural network backpropagation dalam meramal tingkat inflasi bulanan indonesia menghasilkan tingkat akurasi dengan nilai MAD sebesar 0.0577, MSE 0.0069, dan nilai RMSE sebesar 0.0830 .

2. Performa model multiple linear regression dalam meramal tingkat inflasi bulanan indonesia menghasilkan tingkat akurasi dengan nilai MAD sebesar 0.0380, MSE 0.0023, dan nilai RMSE sebesar 0.0481.

3. Performa model multiple linear regression lebih baik dibandingkan dengan neural network bacpropagation dalam meramal tingkat inflasi bulanan indonesia.

\section{REFERENSI}

[1] Badan Pusat Statistik (BPS). 2015. Inflasi, <http://www.bps.go.id/aboutus.php?id_subyek=03\&tabe l=1\&fl=2> Diunduh pada tanggal 03 Desember 2015.

[2] Han, J.,\&Kamber, M. (2006).Data Mining Concept and Tehniques.San Fransisco: Morgan Kauffman. 
[3] Gorunescu, Florin (2011). Data Mining: Concepts, Models, and Techniques. Verlag Berlin Heidelberg: Springer.

[4] Sumathi, \& S., Sivanandam, S.N. (2006). Introduction to Data Mining and its Applications. Berlin Heidelberg New York: Springer.

[5] Witten, I. H., Frank, E., \& Hall, M. A. (2011).Data Mining: Practical Machine Learning and Tools. Burlington: Morgan Kaufmann Publisher.

[6] Kusumadewi, Sri (2010). Pengantar Jaringan Syaraf Tiruan. Yogyakarta.Teknik Informatika FT UII.

[7] Alpaydin, Ethem. (2010). Introduction to Machine Learning. London: The MIT Press.

[8] Vercellis, Carlo (2009). Business Intelligent: Data Mining and Optimization for Decision Making. Southern Gate, Chichester, West Sussex: John Willey \& Sons, Ltd..

[9] Larose, D. T. (2005).Discovering Knowledge in Data. New Jersey: John Willey \& Sons, Inc.

[10] Shukla, A., Tiwari, R., \& Kala, R. (2010). Real Life Applications of Soft Computing. United States of America on: Taylor and Francis Group, LLC.

[11] Maimon, Oded\&Rokach, Lior.(2005). Data Mining and Knowledge Discovey Handbook. New York: Springer.

[12] Sugiyono, (2009). Metode Penelitian Bisnis. Bandung: Alfabeta. 